\title{
Microbiota conjuntival e resistência a antibióticos em recém-nascidos prematuros internados em unidade de terapia intensiva
}

\author{
Conjunctival microbiota and antibiotics resistance in preterm \\ newborns hospitalized in neonatal intensive care unit
}

\author{
Daniela Endriss ${ }^{1}$ \\ Carlos Teixeira Brandt ${ }^{2}$ \\ Célia Maria Machado Barbosa de Castro ${ }^{3}$ \\ Vladimir Fontes Oliveira ${ }^{4}$ \\ Maria de Fátima Alves Diniz ${ }^{5}$
}

Pesquisa realizada no Hospital das Clínicas da Universidade Federal de Pernambuco - UFPE - Recife (PE) Brasil e Laboratório de Imunopatologia Keizo Asami (LIKA) e Fundação Altino Ventura - Recife (PE) - Brasil. Oftalmologista da Fundação Altino Ventura e Hospital de Olhos de Pernambuco - Recife (PE) - Brasil.

${ }^{2}$ Professor Titular de Clínica Pediátrica Cirúrgica da Universidade Federal de Pernambuco - UFPE - Recife (PE) - Brasil.

${ }^{3}$ Professora Adjunta do Departamento de Medicina Tropical da UFPE - Recife (PE) - Brasil.

${ }^{4}$ Aluno do terceiro ano do Curso de Especialização em Oftalmologia da Fundação Altino Ventura - Recife (PE) - Brasil.

Biomédica do Departamento de Microbiologia Clínica do Laboratório de Imunopatologia Keizo Asami (LIKA) da UFPE - Recife (PE) - Brasil.

Endereço para correspondência: Daniela Endriss. Rua do Progresso, 317/604 - Recife (PE) CEP 50070-020 E-mail: danielaendriss@yahoo.com.br

Recebido para publicação em 03.03.2008

Última versão recebida em 13.02.2009

Aprovação em 21.05.2009

Os autores não tem interesse comercial em nenhum dos produtos citados neste estudo.

\begin{tabular}{|c|}
\hline RESUMO \\
\hline Objetivo: Analisar a flora bacteriana da conjuntiva e o padrão de resistên- \\
cia a antibióticos em crianças recém-nascidas prematuras na Unidade de \\
Terapia Intensiva Neonatal (UTIN) do Hospital das Clínicas da Universi- \\
dade Federal de Pernambuco (UFPE). Métodos: Foram analisadas amos- \\
tras de secreção conjuntival de 48 recém-nascidos com permanência de \\
pelo menos 48 horas na UTIN. Resultados: Das 48 amostras 40 (83,3\%) \\
apresentaram cultura positiva, com maior frequência de Staphyloccocus \\
coagulase-negativo (43,2\%) e Staphyloccocus aureus $(25,0 \%)$. Foram \\
consideradas multirresistentes 63,9\% das bactérias. Os antibióticos com \\
maior sensibilidade no antibiograma foram gatifloxacino (97,2\%), van- \\
comicina(94,4\%)e ofloxacino(94,4\%). Conclusões: A florabacteriana da \\
conjuntiva de prematuros na UTIN é diversificada, predominando as \\
bactérias Gram-positivas, geralmente multirresistente a antibióticos.
\end{tabular}

Descritores: Túnica conjuntiva/microbiologia; Resistência microbiana a medicamentos; Infecção hospitalar; Terapia intensiva neonatal; Prematuro

\section{INTRODUÇÃO}

Crianças internadas em unidade de terapia intensiva (UTI) neonatal apresentam numerosos fatores de risco para o desenvolvimento de conjuntivite bacteriana. Entre estes fatores, estão a imaturidade do sistema nasolacrimal, trauma direto da conjuntiva pela manipulação de rotina e exposição da conjuntiva à secreções respiratórias ${ }^{(1-3)}$. A conjuntivite pode ocorrer mais frequentemente em recém-nascidos prematuros por passarem considerável parte do tempo com os olhos fechados ou cobertos, favorecendo a proliferação de bactérias. Além disso, os canais lacrimais não estão completamente pérvios em cerca de $20 \%$ dos neonatos a termo, e este número pode ser ainda maior em neonatos prematuros. A dificuldade na drenagem e consequente acúmulo de lágrima, debris epiteliais e bactérias sobre a superfície ocular, favorecem um meio para crescimento bacteriano ${ }^{(1-2,4)}$.

Afecções oculares em pacientes internados em UTI neonatal, como conjuntivite bacteriana, úlceras e afecções palpebrais, podem evoluir de forma grave $^{(2-6)}$. Essas enfermidades podem ser resultados da interferência, inibição e modificação da flora bacteriana de recém-natos internados em UTI ${ }^{(1)}$. A colonização da conjuntiva por microorganismos pode levar ao maior risco de infecção ocular, e, portanto, a investigação dos fatores responsáveis por este risco aumentado é fundamental para o planejamento de estratégias de 
prevenção destas infecções. A colonização de bactérias na conjuntiva de recém-nascidos internados na UTI pode ser reflexo da bacteremia sistêmica, ou um indício da contaminação primária de bactérias que podem tomar a corrente sanguínea ${ }^{(2)}$.

Frente às condições dos pacientes internados nas UTI neonatal e sua exposição aos inúmeros fatores que podem modificar a flora da conjuntiva nas crianças, possivelmente uma maior quantidade e diversidade de bactérias colonizam a conjuntiva destes pacientes, assim como maior virulência e resistência aos antimicrobianos por parte desses microrganismos, em relação à microflora de neonatos que não frequentam a UTI ${ }^{(4)}$.

Em face de não existir relato da microbiota da conjuntiva em recém-nascidos no Brasil, o presente estudo tem como objetivo estudar a microbiota da conjuntiva e o padrão de resistência a antibióticos em recém-nascidos prematuros internados na UTI neonatal do Hospital das Clínicas da Universidade Federal de Pernambuco (UFPE).

\section{MÉTODOS}

Foi realizado estudo prospectivo, observacional, tipo corte transversal, em recém-nascidos prematuros internados na Unidade de Terapia Intensiva Neonatal (UTIN) do Hospital das Clínicas da UFPE. A amostra foi constituída de 48 recémnascidos, escolhidos ao acaso, com idade gestacional inferior a 37 semanas, internados na UTIN por mais de 48 horas, sem história prévia ou atual de doença ocular, independente do tipo de parto ou do tempo de ruptura da bolsa amniótica. Todos os recém-nascidos foram submetidos ao método de Credé de rotina.

As informações sobre sexo, peso, data de nascimento e data da alta hospitalar, tipo de parto, uso de antibióticos sistêmicos e tempo de uso, icterícia, fototerapia, septicemia e bolsa amniótica rota foram coletadas dos prontuários dos pacientes. A ruptura da bolsa amniótica foi considerada como fator de risco quando superior a 3 horas. A fototerapia foi considerada como fator de risco quando superior a três dias.

O conteúdo do fundo de saco inferior dos recém-nascidos foi coletado com "swab", por dois médicos oftalmologistas, sem tocar as pálpebras ou cílios e colocado em meio de transporte Stuart. O "swab" foi previamente umedecido com soro fisiológico a $0,9 \%$, estéril. O material coletado foi imediatamente levado ao Laboratório de Microbiologia do Laboratório de Imunopatologia Keizo Asami (LIKA) para análise.

A partir do material coletado foram realizadas bacterioscopias e semeaduras, com isolamento, identificação de bactérias e confecção de antibiogramas. Para cultivo de bactérias foram usadas duas placas (Ágar-sangue e Ágar-Levino). As placas foram incubadas a temperatura de $36^{\circ} \mathrm{C} \pm 1^{\circ} \mathrm{C}$ por 24 a $48 \mathrm{~h}$ e nos casos de cultura positiva para bactérias aeróbicas, foi realizado antibiograma. Os microorganismos isolados foram submetidos ao teste de sensibilidade por difusão em discos. A leitura foi feita medindo-se o diâmetro do halo de inibição ao redor do disco, tendo sido testado para 11 antibióticos (ceftriaxona, tobramicina, vancomicina, gatifloxacino, ciprofloxacino, gentamicina, cloranfenicol, ofloxacino, oxacilina, cefalotina e gentamicina). Foram considerados multirresistentes os casos de bactérias com resistência a quatro ou mais tipos de antibióticos e de baixa resistência os que eram resistentes a menos de quatro antibióticos.

As variáveis quantitativas foram expressas por suas médias e respectivos desvios-padrão. Para comparar as médias de dois grupos utilizou-se o teste $t$ de Student para amostras independentes. As variáveis qualitativas foram expressas por suas frequências. As diferenças entre frequências foram analisadas pelo teste exato de Fisher. O teste de Mann-Whitney foi utilizado para comparar as distribuições do tempo de internamento no momento da coleta com a ocorrência de culturas positivas para Staphylococcus coagulase-negativo (SCoN) e outras bactérias não-SCoN. p<0,005 foi usado para rejeição da hipótese de nulidade.

A pesquisa foi aprovada pelo Comitê de Ética em Pesquisa da Fundação Altino Ventura.

\section{RESULTADOS}

O tempo de internação dos recém-nascidos na UTI variou de quatro a 69 dias, média de $24,3 \pm 17,0$ dias. Vinte e seis $(54,2 \%)$ eram do sexo masculino e $22(45,8 \%)$ do feminino. $\mathrm{O}$ peso ao nascimento variou de 600 a $2.490 \mathrm{~g}$, média de $1.600 \pm$ $460 \mathrm{~g}$. A idade gestacional ao nascimento variou de 24 a 37 semanas, média de $33 \pm 2,5$ semanas. Quanto ao tipo de parto, $24(50,0 \%)$ foi cesárea e $24(50,0 \%)$ por via vaginal. A coleta de material para cultura ocorreu do segundo aos $67^{\circ}$ dia de internamento, em média $9 \pm 11$ dias, no período de janeiro a outubro de 2006.

Quarenta e um $(85,4 \%)$ recém-nascidos estavam em uso de antibióticos sistêmicos no momento da coleta da amostra. Dos que estavam em uso de antibióticos, 27 (65,9\%) fizeram uso de dois ou mais tipos. Os antibióticos sistêmicos mais frequentemente usados foram penicilina cristalina e gentamicina em 37 $(90,2 \%)$ casos. Outros antibióticos sistêmicos descritos foram ampicilina, amicacina, vancomicina, ciprofloxacino e oxacilina.

Os recém-nascidos incluídos no estudo tiveram múltiplos diagnósticos. Os mais frequentes foram: icterícia em $43(89,6 \%)$ e septicemia em $25(52,1 \%)$. Trinta e quatro $(70,8 \%)$ casos receberam fototerapia por mais de três dias. A ruptura da bolsa amniótica por mais de três horas foi diagnosticada em 13 $(27,1 \%)$ casos.

A bacterioscopia foi positiva em $45(93,7 \%)$ das 48 amostras coletadas. Bactérias Gram-positivas foram identificadas em todas as 45 lâminas positivas. Em duas lâminas também foram identificadas bactérias Gram-negativas, revelando padrão misto. Em três lâminas $(6,3 \%)$ não houve identificação de bactérias.

A cultura da secreção conjuntival foi positiva em 40 (83,3\%) recém-nascidos e negativa em oito $(16,7 \%)$. Foram encontradas nove espécies diferentes de bactérias. Em 37 (92,5\%) das 40 
culturas positivas houve crescimento de apenas uma bactéria e em três $(7,5 \%)$ foram identificadas mais de uma espécie. Destas, em uma cultura foram identificadas três espécies de bactérias (SCoN, Pseudomonas aeruginosa, Corynebacterium $\mathrm{sp}$.) e nas outras foram identificadas duas espécies de bactérias (em uma Staphylococcus saprophyticus e Corynebacterium sp., e na outra houve crescimento de duas colônias separadas de SCoN, inclusive com antibiogramas distintos), perfazendo 44 isolados de bactéria. Trinta e quatro isolados (77,3\%) foram de bactérias Gram-positivas, dois (4,5\%) de Gramnegativas, e oito $(18,2 \%)$ de anaeróbicas. Foi observado o predomínio do SCoN em 19 (43,2\%) dos 44 isolados (Tabela 1).

Embora o grupo de recém-nascidos com cultura positiva tenha permanecido na UTI por mais tempo (média 25,6 $\pm 17,0$ dias) do que aqueles que tiveram cultura negativa (média de 21,2 $\pm 18,0$ dias), a diferença não alcançou significância estatística $(\mathrm{p}=0,44)$. Não houve diferença estatisticamente significante entre os grupos com cultura positiva e negativa em relação: ao tipo de parto $(\mathrm{p}=0,65)$; ao uso de antibióticos sistêmicos $(\mathrm{p}=0,25)$; ao diagnóstico de septicemia $(\mathrm{p}=0,30)$; à ocorrência de ruptura da bolsa amniótica como fator de risco $(\mathrm{p}=0,17)$; icterícia $(\mathrm{p}=0,27)$; e ao tratamento com fototerapia como fator de risco $(\mathrm{p}=0,24)$.

Na ocasião da coleta do material do saco conjuntival, o grupo de recém-nascidos com culturas positivas para $\mathrm{SCoN}$ (19 amostras, 43,2\%) estava internado por tempo significantemente maior na UTI ( $11 \pm 7$ dias), do que o grupo não-SCoN ( 25 amostras, $56,8 \%$ ), internados com uma média de $9 \pm 15$ dias $(\mathrm{p}=0,03)$.

O antibiograma foi realizado em 36 isolados de bactérias aeróbicas, sendo consideradas multirresistentes $23(63,9 \%)$ e de baixa resistência $13(36,1 \%)$. A resistência aos antimicrobianos não teve relação estatisticamente significante com: peso ao nascimento ( $\mathrm{p}=0,62)$; tempo de internação $(\mathrm{p}=0,82)$; uso de antibióticos sistêmicos $(\mathrm{p}=0,19)$; e tratamento com fototerapia $(\mathrm{p}=0,23)$. Apesar de não haver significância estatística 18 (78,3\%) dos 23 isolados de bactérias multirresistentes foram de prematuros que estavam em uso de antibióticos sistêmicos. Em crianças

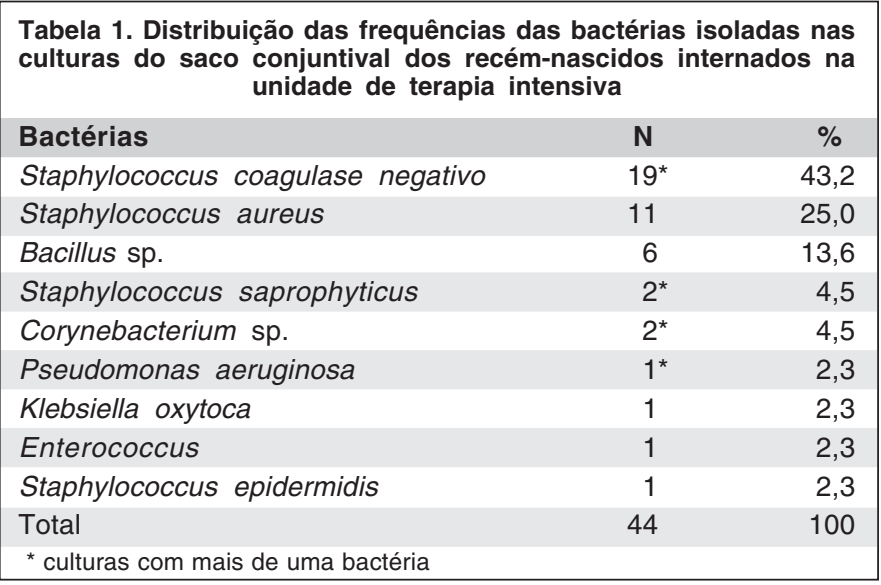

com o diagnóstico de septicemia, houve uma tendência das bactérias a apresentar maior resistência aos antimicrobianos em relação àquelas cultivadas nos recém-nascidos que não apresentaram septicemia; no entanto, esta tendência não alcançou significância estatística $(\mathrm{p}=0,10)$.

As bactérias apresentaram maior sensibilidade ao antibiótico gatifloxacina, e menor sensibilidade a tobramicina (Tabela 2). A tabela 3 mostra a distribuição das frequências de sensibilidade das bactérias Gram-positivas aos antimicrobianos.

\section{DISCUSSÃO}

A identificação dos principais microrganismos nosocomiais presentes nos recém-nascidos internados na UTI, e seu padrão de resistência a antibióticos são importantes, não apenas na identificação das possíveis fontes de contaminação, como também na escolha do antibiótico adequado, evitando retardo no tratamento clínico eficaz ${ }^{(2,7)}$.

A cultura da secreção da conjuntiva é um procedimento não invasivo e praticamente inofensivo ao recém-nascido, que auxilia na identificação das bactérias colonizadoras do saco conjuntival ${ }^{(4)}$. A presença de bactérias nosocomiais na conjuntiva de neonatos pode refletir a colonização bacteriana da conjuntiva precedendo a bacteremia ou como um resultado desta. Existe um relato da semelhança da cultura do saco conjuntival e do sangue em $35 \%$ dos neonatos internados em UTI ${ }^{(2)}$.

A colonização bacteriana aumenta ao longo da internação de neonatos na UTI ${ }^{(8)}$. Após a segunda semana de internação, não há influência do tipo de parto, nem da ocorrência de ruptura precoce da bolsa amniótica, nem da flora do canal de parto na microbiota da conjuntiva, que estaria relacionada diretamente às inoculações do próprio meio ambiente ${ }^{(9)}$. No presente estudo, o grande número de culturas positivas $(83,3 \%)$ não teve relação estatisticamente significante com o tempo de internação dos recém-nascidos. A maior parte das coletas $(81,2 \%)$ ocorreu durante os primeiros dez dias de internação, evidenciando que a colonização da conjuntiva por bactérias pode ocorrer precocemente. Estes dados apontam para a necessidade da vigilância quanto aos cuidados dos profissionais de saúde e risco de infecções nosocomiais desde os primeiros dias de internamento dos recém-nascidos na UTI ${ }^{(4)}$. Além disto, é possível que as crianças internadas por mais tempo na UTI tenham sido submetidas a múltiplos esquemas de antibióticos sistêmicos, interferindo na colonização bacteriana do saco conjuntival, e, portanto, no resultado das culturas.

A alta frequência de culturas positivas $(83,3 \%)$ em recémnascidos prematuros internados na UTI, em uso de antibióticos sistêmicos na maior parte dos casos $(85,4 \%)$, reforça as evidências da influência do ambiente neste tipo de colonização. A antibioticoterapia sistêmica não influenciou na ocorrência de colonização bacteriana da conjuntiva, mas pode ter contribuído para a seleção de cepas multirresistentes.

A positividade das culturas de secreção da conjuntiva não teve associação significante com o tipo de parto, o uso de 
antibióticos sistêmicos, diagnóstico de septicemia, icterícia e fototerapia como fator de risco. Houve uma tendência, apesar de não haver significância estatística, de maior número de culturas positivas nos casos com ruptura da bolsa amniótica por mais de três horas $(\mathrm{p}=0,17)$. Possivelmente uma amostra maior poderia comprovar esta associação, já anteriormente observa$\mathrm{da}^{(9)}$. A ruptura prolongada da bolsa amniótica também está relacionada ao maior risco de septicemia ${ }^{(10)}$. O conhecimento destes fatores de risco é importante, pois alguns deles podem ser controlados através de educação continuada e melhor direcionamento dos programas de controle de infecção ${ }^{(1)}$.

O exame bacterioscópico direto (método de Gram) é fundamental na investigação de doenças oculares externas ${ }^{(5)}$. $\mathrm{Na}$ amostra estudada a bacterioscopia foi positiva em 93,7\% dos casos, maior do que o número de culturas positivas $(83,3 \%)$. Uma hipótese para a diferença na positividade da bacterioscopia e da cultura da secreção conjuntival poderia ser a pequena quantidade de bactérias presentes em algumas amostras, não tornando possível o crescimento de colônias apesar do enriquecimento com o meio de cultura. Possivelmente, o uso de antibióticos sistêmicos tenha interferido nesta quantidade de bactérias $^{(5)}$.

\begin{tabular}{|c|c|c|}
\hline Bactérias / Antimicrobianos & $\mathrm{n}=36$ & $\%$ \\
\hline Tobramicina & 10 & 27,8 \\
\hline Oxacilina & 13 & 36,1 \\
\hline Ceftriaxona & 17 & 47,2 \\
\hline Ciprofloxacino & 19 & 52,8 \\
\hline Gentamicina & 20 & 55,6 \\
\hline Cloranfenicol & 23 & 63,9 \\
\hline Cefalotina & 26 & 72,2 \\
\hline Neomicina & 26 & 72,2 \\
\hline Ofloxacino & 34 & 94,4 \\
\hline Vancomicina & 34 & 94,4 \\
\hline Gatifloxacino & 35 & 97,2 \\
\hline
\end{tabular}

É relatada a colonização bacteriana como um importante fator predisponente a infecção ${ }^{(1)}$. Alguns recém-nascidos que permanecem em UTI por tempo prolongado podem atuar como reservatório de microrganismos patogênicos e/ou multirresistentes a antibióticos, e transmitirem através da manipulação por profissionais de saúde a outros neonatos admitidos na mesma $\operatorname{sala}^{(8)}$. A identificação desta possível fonte de contaminação é útil na adoção de medidas profiláticas durante os procedimentos de rotina. Além disso, este fluxo pode justificar a ocorrência de bactérias multirresistentes na conjuntiva de neonatos recém-internados na UTI e não apenas nos que estão por tempo prolongado.

Um protocolo de cuidados na manipulação dos neonatos e medidas antissépticas é fundamental na rotina da UTI. No entanto, outros aspectos merecem tamanha atenção: lesão traumática do epitélio conjuntival pode ser provocada acidentalmente durante intervenções terapêuticas como uso de máscara de ventilação ou protetores oculares na fototerapia. Além disso, a conjuntiva pode estar exposta a secreções nasofaríngeas direta ou indiretamente, por gotículas em suspensão, resultando na contaminação desta mucosa ${ }^{(2,4,8)}$.

O SCoN é o microorganismo mais encontrado na conjuntiva de neonatos internados em UTI, na presença ou ausência de sinais clínicos de conjuntivite, segundo alguns autores ${ }^{(1-2,7)}$. No presente estudo, houve predomínio do SCoN $(43,2 \%)$ nas amostras de cultura de secreção conjuntival, concordando com os achados na literatura. As variações regionais também devem ser levadas em consideração.

No estudo atual, foi observado aumento na colonização da conjuntiva por bactérias SCoN ao longo do tempo de internamento na UTI, em relação às bactérias não-SCoN. Esta associação pode ser devida à exposição a antimicrobianos, intervenções terapêuticas, entre outros fatores ${ }^{(2)}$. Este achado é relevante para o conhecimento da variação de colônias bacterianas na conjuntiva ao longo do tempo de internamento dos neonatos na UTI, e programação de esquemas antibióticos para maior cobertura aos patógenos mais frequentemente presentes de acordo com o número de dias internados.

Tabela 3. Distribuição das frequências da sensibilidade das bactérias Gram-positivas aos antimicrobianos

\begin{tabular}{|c|c|c|c|c|c|}
\hline $\begin{array}{l}\text { Bactérias Gram + I } \\
\text { Antimicrobianos }\end{array}$ & $\begin{array}{c}\text { SCoN } n=19 \\
\%\end{array}$ & $\begin{array}{c}\text { S. aureus } \mathrm{n}=11 \\
\%\end{array}$ & $\begin{array}{c}\text { S. saprophyticus } \mathrm{n}=2 \\
\%\end{array}$ & $\begin{array}{c}\text { Enterococcus } \mathrm{n}=1 \\
\%\end{array}$ & $\begin{array}{r}\text { S. epidermidis } \mathrm{n}=1 \\
\%\end{array}$ \\
\hline Tobramicina & 10,5 & 45,5 & 100,0 & 0 & 100 \\
\hline Oxacilina & 26,3 & 45,5 & 50,0 & 0 & 100 \\
\hline Ceftriaxona & 31,6 & 54,5 & 50,0 & 0 & 100 \\
\hline Ciprofloxacino & 36,8 & 72,7 & 0 & 100 & 100 \\
\hline Gentamicina & 31,6 & 72,7 & 100,0 & 100 & 100 \\
\hline Cefalotina & 68,4 & 72,7 & 50,0 & 0 & 100 \\
\hline Cloranfenicol & 63,2 & 81,8 & 100,0 & 100 & 100 \\
\hline Neomicina & 63,2 & 72,7 & 100,0 & 100 & 100 \\
\hline Ofloxacino & 89,5 & 100,0 & 100,0 & 100 & 100 \\
\hline Vancomicina & 100,0 & 100,0 & 100,0 & 100 & 100 \\
\hline Gatifloxacino & 100,0 & 90,9 & 100,0 & 100 & 100 \\
\hline
\end{tabular}


A resistência aos antibióticos vem aumento com a disseminação e maior tempo de uso destes na população ${ }^{(12)}$. Os antibióticos testados no presente estudo são frequentemente usados no tratamento e profilaxia de afecções oftalmológicas, assim como em quadros sistêmicos. Um dado alarmante observado neste estudo é a alta frequência de bactérias multirresistentes $(63,9 \%)$ colonizando o saco conjuntival de neonatos internados na UTI. O tempo de internamento e o uso de antibióticos sistêmicos são variáveis conhecidas que influenciam na multirresistência bacteriana descrita na literatura ${ }^{(13)}$. No entanto, a falta de influência significante destes fatores na multirresistência bacteriana no presente estudo pode ser devida ao tamanho da amostra estudada, ou ao tempo insuficiente de internamento dos recém-nascidos, ou devido a alguma fonte de contaminação em comum que esteja disseminando aleatoriamente bactérias multirresistentes através dos profissionais de saúde.

Os antibióticos que apresentam melhor eficácia para o tratamento de eventual infecção ocular por Gram-positivos são a vancomicina e gatifloxacino com sensibilidade acima de $90 \%$. No caso de Gram-negativos, os antibióticos com melhor eficácia são neomicina, ceftriaxona, gentamicina, ciprofloxacino e ofloxacino.

Um aspecto importante a ser considerado no presente estudo, é que o teste de sensibilidade a antibióticos (antibiograma) é realizado in vitro e pode não refletir a real eficácia destes antibióticos in vivo. Além disso, o teste de sensibilidade por difusão em discos é baseado na concentração sérica de antibióticos que pode ser diferente da concentração na conjuntiva após o uso de colírios tópicos. O presente estudo é importante na orientação da escolha do antibiótico ideal para tratamento de afecções oculares ou na profilaxia pós-cirurgias oftalmológicas.

\section{CONCLUSÕES}

A flora bacteriana da conjuntiva de prematuros na UTIN é diversificada, predominando as bactérias Gram-positivas, geralmente multirresistente a antibióticos.

\section{ABSTRACT}

Purpose: To analyze the conjunctival bacterial flora and the antibiotics resistance pattern in preterm newborns at the Neonatal Intensive Care Unit (NICU), in "Hospital das Clínicas da Universidade Federal de Pernambuco - UFPE”. Methods: Mate- rial from the conjunctival sac was obtained from 48 premature infants eyes that stayed at in NICU more than 48 hours. Results: Culture analysis revealed that $40(83.3 \%)$ were positive and the pathogens most commonly isolated included Coagulase-negative Staphylococcus (43.2\%) and Staphylococcus aureus $(25.0 \%)$, being $63.9 \%$ of the bacteria multiresistant. Antimicrobial test results demonstrated great sensitivity to gatifloxacin (97.2\%), vancomycin (94.4\%) and ofloxacin (94.4\%). Conclusions: Conjunctival bacterial flora among newborns in NICU is varied, mainly Gram-positive, usually multiresistant to antibiotics.

Keywords: Conjunctiva/microbiology; Drug resistance; Cross infection; Intensive care, neonatal; Infant, premature

\section{REFERÊNCIAS}

1. Haas J, Larson E, Ross B, See B, Saiman L. Epidemiology and diagnosis of hospital-acquired conjunctivitis among neonatal intensive care unit patients. Pediatr Infect Dis J. 2005;24(7):586-9.

2. Raskind CH, Sabo BE, Callan DA, Farrel PA, Dembry ML, Gallagher PG. Conjunctival colonization of infants hospitalized in a neonatal intensive care unit: a longitudinal analysis. Infect Control Hosp Epidemiol. 2004;25(3):216-20.

3. Araújo WF, Yamazaki ES, Susuki Jr. ER, Cuevas IAB, Grupenmacher F. Estudo da microbiota da flora conjuntival em pacientes internados em UTI. Rev Bras Oftalmol. 2001;60(11):771-5.

4. Oliveira VF, Brandt CT, Castro CMMB, Endriss D, Carvalho K. Flora bacteriana conjuntival e padrão de resistência a antibióticos em crianças recém-nascidas internadas em UTI. An Fac Med Univ Fed Pernamb, Recife. 2005;50(1):41-4.

5. Campos MSQ, Guidugli T, Lima ALH, Freitas LL. Conjuntivites: análise clínico-laboratorial. Arq Bras Oftalmol. 1998;51(5):194-96.

6. Fagá IMA, Fernandez YMA, Figueroa AG. Flora bacteriana conjuntival del neonato y la respuesta a la profilaxis oftálmica empleada. Arch Venez Puer Pediatri. 2004;67(1):27-33. Italian.

7. Iroha EA, Kesah CN, Egri-Okwagi MT, Odugbemi TO. Bacterial eye infection in neonates, a prospective study in a neonatal unit. West Afr J Med. 1998;17(3): $168-72$.

8. Almuneef MA, Baltimore RS, Farrel PA, Reagan-Cirincione P, Dembry LM. Molecular typing demonstrating transmission of gram-negative rods in a neonatal intensive care unit in the absence of a recognized epidemic. Clin Infect Dis. 2001; 32(15):220-7.

9. Farah ALHL, Santos MAA, Belfort R, Cabral JH, Mós EM, Farah ME. Microbiota anaeróbia e facultativa da conjuntiva normal de recém-nascidos. Arq Bras Oftalmol. 1993;56(3):138-45.

10. Brook I, Barrett CT, Brinkman III CR, Martin WJ, Finegold SM. Aerobic and anaerobic bacterial flora of the maternal cervix and newborn gastric fluid and conjunctiva: a prospective study. Pediatrics. 1979;63(3):451-55.

11. Goldmann DA. The bacterial flora of neonates in intensive care-monitoring and manipulation. J Hosp Infect. 1988;11(Suppl A):340-51.

12. Arantes TEF, Cavalcanti RF, Diniz MFA, Severo MS, Lins Neto J, Castro CMMB. Conjunctival bacterial flora and antibiotic resistance pattern in patients undergoing cataract surgery. Arq Bras Oftalmol. 2006;69(1):33-6.

13. Glasgow TS, Young PC, Wallin J, Kwok C, Stoddard G, Firth S, et al. Association of intrapartum antibiotic exposure and late-onset serious bacterial infections in infants. Pediatrics. 2005;116(3):696-702. 